\title{
The Determinants of Household Electricity Demand in Marginal Ecuador: "A Case Study at Monte Sinai"
}

\author{
José Hidalgo, MSc. ${ }^{1}$, Silvia Coello, Mg. ${ }^{2}$, and Yomar González, PhD. ${ }^{3}$ \\ ${ }^{1}$ University of Guayaquil, Ecuador, jose.hidalgocr@ug.edu.ec, yomar.gonzalezc@ug.edu. \\ ${ }^{2}$ University of Guayaquil, Ecuador, silvia.coellop@u.edu.ec
}

\begin{abstract}
Electricity demand has grown in almost $75 \%$ in the last ten years, and with the addition of 900 thousand new families from rural and marginal areas to the electricity grid, total electricity demand may increase significantly. The understanding of the specific energy consumption patterns of these sectors could explain the influence on the electricity demand and lead the regional government policy to promote their formal electricity access. However, micro level analysis may show different correlations among determinants than those usually reported in previous macro models. The data was taken from a convenience sample of 190 socio-economic surveys at Monte Sinai in order to obtain a system of electricity demand equations and elasticity using Tobit regression model
\end{abstract}

\section{INTRODUCTION}

In recent years, many studies have been conducted about Ecuador's energy mix. These studies focus on macro-level analysis in order to estimate the electricity demand. In 2013, the departments of Electricity and Renewable Energies, Coordination of Strategic Sectors and the National Electricity Council (CONELEC) established a Master Electrification Plan for 2013-2022. The econometric study relates macroeconomic variables such as, Gross Domestic Product (GDP) and growth patterns with the consumption of electricity. However, there exist significant differences between and within regions of the country. In Ecuador, almost $56 \%$ of the population lives in urban-marginal $(19.3 \%)$ and rural areas $(37 \%)$, according to the census of population and housing carried out in 2010 by the National Institute of Statistics and Censuses (INEC). A macroeconomic analysis may be too wide to explain consumption behavior (Chen et al., 2005) given that socioeconomic conditions in such areas differ greatly. Howorth et Al. (2013), express that in determining national supply-demand, energy balances for developing countries usually distinct between urban and rural household consumption, but rarely consider the total urban energy system. In particular, factors determining use of electricity by households need to be analyzed for these areas.

Several studies have been conducted on correlating certain socio-economic characteristics with energy consumption. Some of them focus on micro-level energy consumption using household survey data. Differences in income level, labor access and education are likely to affect household decisions on electricity consumption.

Digital Object Identifier (DOI): http://dx.doi.org/10.18687/LACCEI2018.1.1.312 ISBN: 978-0-9993443-1-6

ISSN: $2414-6390$
Sukarno et Al. (2017), pointed out that households' lifestyles and energy consumption are closely related and, that lifestyle is influenced by income level, family patterns and other factors. Ery and Tezuka (2013), showed that in Bandung, family size, time spent at home, education level, home appliances and lighting had a significant, positive effect on the monthly electricity bill. Niu et Al (2016) used household income, price of electricity, all kinds of electrical appliances, purchase price of main appliances, and other variables to fully reflect behavior, preferences and living patterns of sample households in electricity use and provided the basis for analyzing the relationship between household electricity consumption and the quality of life. Di Cosmo et O'Hora (2017) determined a relation among consumption patterns of electricity and electricity tariffs. Yalcintas et Kaya (2017) suggested the importance of dwelling type, lifestyle and household size in the electricity consumption. Anggun et $\mathrm{Al}$ (2016) and Xie et Al (2016) showed that family members' size are positive and give significant effect to household demand electricity consumption in Malang, Indonesia and Sichuan province, China respectively. Guo et Al (2017), indicate that family disposable income (utility) reflect the economic situation of a family and can influence the electricity consumption of the household. Esmaeilimoakher et Al (2016) used disposable household income as a measure for evaluating the relationship between households' income and the average annual electricity consumption in the dwellings.

These studies provide some important insights into which determinants influence household electricity consumption patterns given that non previous studies were found for Ecuador. Homes are the basic units of electricity consumption, therefore the reduction of electricity consumption per household will reduce the electricity consumption of the whole country. Such investigation into electricity use in marginal areas is particularly important today when Ecuador's electricity coverage is increasing so fast. Given these conditions, this study aims to address these important issues by empirically examining electricity demand in marginal Ecuador.

To research this topic, we implemented a random household survey of Monte Sinai's twelve neighborhoods in July of 2017. The collected data contain general information on electricity consumption and potential determinants, such as household characteristics, income and utility. There are two main reasons to use survey data from this sector. First, the high heterogeneity in the households regarding their general

16 $^{\text {th }}$ LACCEI International Multi-Conference for Engineering, Education, and Technology: "Innovation in Education and Inclusion", 19-21 July 2018, Lima, Peru. 
characteristics and socio-economic levels. Therefore, we can easily obtain a great diversity of data by conducting a survey in a relative small area.

The second reason is associated with the effects of government policies in this area. Specifically, the Electricity Master Plan 2009-2020, published by CONELEC, which establishes the objective of rural powering and urban-marginal electrification, the program "Enlighten your neighborhood" promoted by the vice-presidency and the legalization of the household being done by the Department of Urban Development and Housing (MIDUVI).

With this unique survey of household data, we estimated a system of electricity demand within a single framework and the elasticities of their corresponding crucial determinants. This approach enabled us to determine the influence of these determinants in the per capita consumption of electricity for this marginal area of the country.

We obtained two important results. First, 73 households $(38.42 \%)$ live with salaries under the basic considered in the country $\$ 366.00$. Second, per capita income has a positive impact on the per capita consumption of electrical energy. In addition, both the ratio of educated household and labor force per household size increases the consumption of electricity.

Overall, our results suggest a potential impact of these marginal areas in the total demand of electricity of the country. If the Ecuadorian government doesn't develop appropriate policies for electricity consumption and efficiency for these areas then the availability of electricity for selling is likely to decline in the near future.

\section{THE STUDY AREA}

The present paper is based on experiences from fieldwork carried in Monte Sinai. It is predominantly a marginal area with people largely depending on artisan jobs. It is located in the northwest side of the city of Guayaquil, Ecuador. According to INEC, the total population in Monte Sinai was 39,802 in 2010; meanwhile in 2017, MIDUVI reported a total population of 131,679 inhabitant which represents an increase of almost $231 \%$ within an approximate area of 782 ha.

This area shows much variation with respect to socioeconomic conditions and electricity consumption and it's considered to be representative for the marginal areas of the country. One hundred and ninety households were selected randomly and interviewed on electricity consumption, demographic characteristics, production and consumption in July 2017. They account for $1.15 \%$ of all houses residing in the selected area. The data covers the monthly and yearly average values of income, expenses and electricity consumption.

\section{II.1 CASE STUDY DESIGN}

In order to understand how socioeconomic factors influence the electricity demand of marginal areas in Ecuador, the present paper shows a case study approach. The selected sample of the 12 neighborhoods was made in proportion to the number of households per neighborhood. The case study is composed of two fundamental parts: data collection and an analysis phase. The data collection phase encompasses the stage of problem formulation and the definition of the research questions. That phase was designed starting from a preliminary overview of the Ecuadorian energy sector that raised several interrogatives regarding socio-economic aspects and their influence in energy consumption, specifically electricity.

To answer these interrogatives a survey was elaborated to engage the inhabitants of this area to answer questions in order to get insights of their livelihoods and socio-economic conditions. During the design of the surveys, questions were set to understand the electricity needs and demand, income and utility per household, consumption patterns, access to education and electricity and to obtain perceptions of the quality of lives they have.

Once the data collection phase was completed, the analysis stage tried to build a coherent connection between the empirical evidence and the propositions advanced in the first phase. In particular, the case study has been designed to shed light on the following issues:

- Socioeconomic aspects: detail exploration of the econometrics of the selected marginal area.

- Incidence on the electrical consumption: determine how the socio-economics aspects affect the use of electricity of the households in this marginal area.

\section{2 SOCIO-ECONOMIC CHARACTERISTICS}

Table 1. provides an overview of the socio-economic characteristics of the surveyed households. In general, the labor force is 1.23 of 4.10 people per household. From the 2.27 people per household over the age of 18 , only 1.70 people had received or is currently studying high school education. The average monthly income and expenses per capita are $\$ 106.85$ and $\$ 84.13$ respectively. Each household saves in average $\$ 86.94$ yearly.

Figure 1. shows that most of the expenses of each household goes to food and beverages with $58.74 \%$ and payment of credits or rent with $9.28 \%$. Figure 2 . shows that almost $50 \%$ of households are made of wood or of mixed composition (wood plus brick) and approximately $45 \%$ are made of brick or concrete. 
Table 1.

SOCIO-ECONOMIC CHARACTERISTICS AND PER CAPITA ENERGY USE OF SURVEYED HOUSEHOLDS

\begin{tabular}{lr}
\hline Household size & 4.10 \\
Labor Force & 1.23 \\
People Over 18 years old & 2.27 \\
People Over 65 years old & 0.08 \\
Mid-education & 1.70 \\
Per capita income (one month) (USD) & 106.8 \\
Per capita expenses (one month) (USD) & 84.13 \\
Household savings (one year) (USD) & 86.94 \\
Average LPG tank of 15 kg price (USD) & 2.5 \\
Average household LPG tank consumption (yearly) & 27 \\
Average cost of electricity (\$/kWh) & 0.093 \\
Average Electricity Consumption (\$/household) & 9.80 \\
Electricity Consumption (kwh/day) & 3.51 \\
Sample Size (Households) & 190 \\
\hline
\end{tabular}

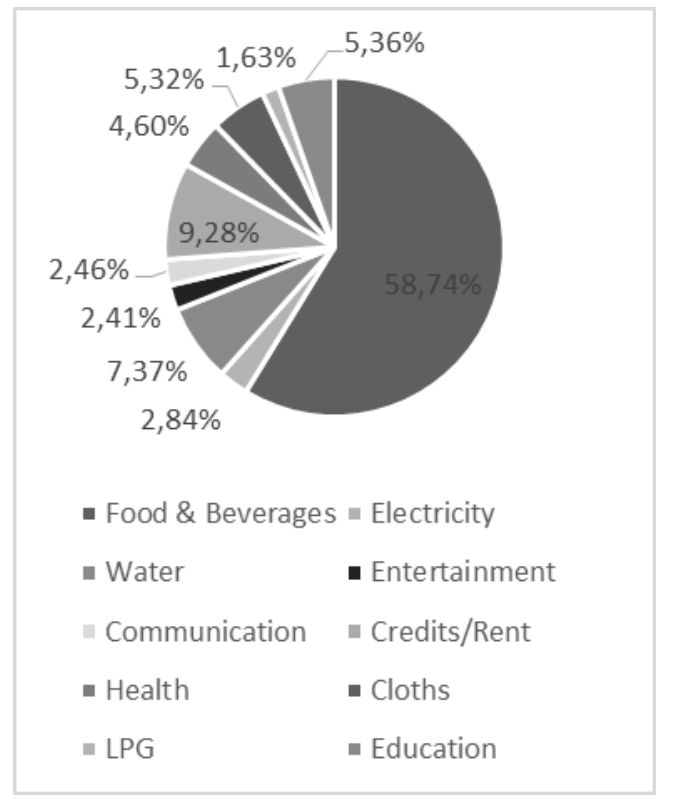

Figure 1. Household's monthly per capita expenses distribution

\section{II.3 ELECTRICAL CHARACTERISTICS}

Table 2. shows the electrical characteristics of the households in the area. Out of the 190 households, $71.39 \%$ of the electrical connections were made in an artisan way. The approximate size of the households is $105.42 \mathrm{~m} 2$, and each have an average of 6.23 electrical appliances. Within the households with access to electricity, only $73.03 \%$ have breaker boxes and $46.50 \%$ of the connections are grounded.
Finally, $31.93 \%$ of the users claim that the lights inside flicker. In Figure 3. it can be seen that $45.17 \%$ have their electrical connections outside the wall and $34.20 \%$ have them inside.

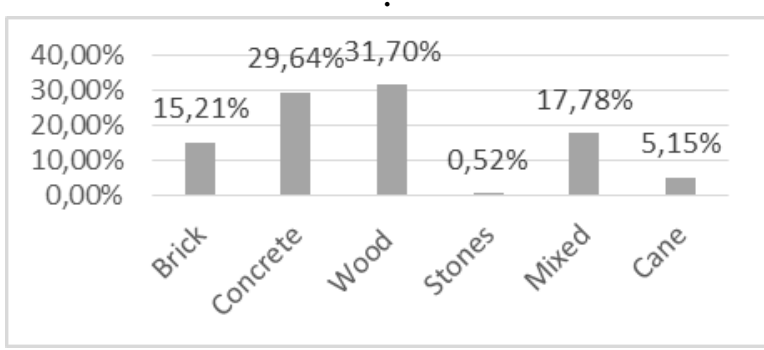

Figure 2. Household's material composition

Table 2.

ELECTRICAL CHARACTERISTICS OF SURVEYED HOUSEHOLDS

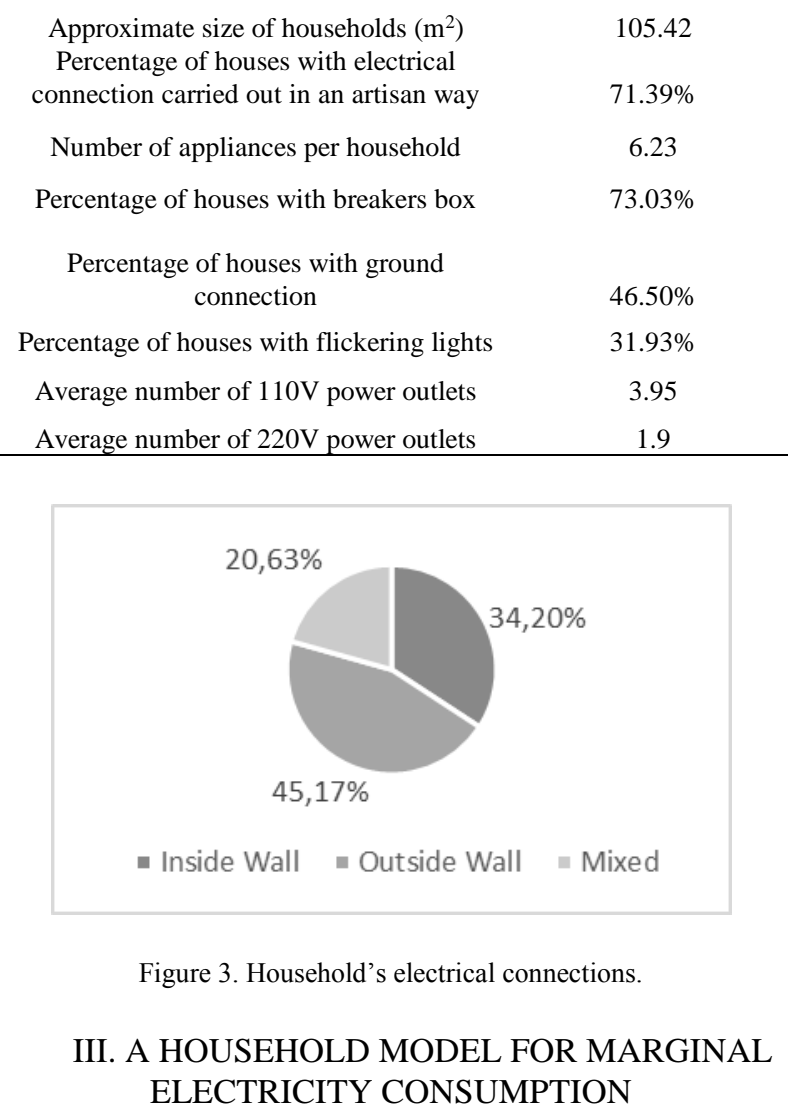

In section 2, it is found that LPG and electricity are the two sources of energy used in this area. LPG is only used for cooking by the interviewed households. Grid electricity is used to give power to all electrical appliances and in small cases for cooking. We therefore focus the analysis on electricity consumption. Given that the electricity tariffs for the area are constant, this factor is not consider in the model.

16 $^{\text {th }}$ LACCEI International Multi-Conference for Engineering, Education, and Technology: "Innovation in Education and 
Various studies have attempted to measure the social and economic determinants of electricity use for rural populations. Kemmler (2007), used a binary choice model consistent with a discrete choice network to analyze the determinants that make a household whether to use electricity or not. Wei et Al., applied the fractional logit regression approach because of the lack of information on energy prices faced by households and that de data was taken for one month. For this marginal area is expected that households maximize profit and allocate resources subject to the level of income and disposable income (utility) of the household. Other determinants such as Labor and Education per household also influence the consumption even though the income or utility of the family is low.

Our model builds on two previous studies that analyze household energy use in rural areas of developing countries. Chen et Al (2005), modeled and estimated choices in labor allocation and energy demand of rural households from available data of three villages in Jiangxi Province, Southeast China using a nonseparable household model. Jingchao and Kotani (2011), analyzed the determinants of energy choices in Beijing's rural households using a framework of non-separable model because many of the subjects are peasants where production and consumption decisions are usually made jointly in a non-separable fashion.

The purpose of this study is to analyze the determinants of electricity consumption in Ecuador's marginal households. A central hypothesis of the paper is that households increase electricity consumption due to higher incomes and utility. In addition, the ratio of the number of people that work and are at least mid-educated by household size decreases the electricity consumption. This study covers one dependent variable: the per capita consumption of electricity (DE). Following Jingchao and Kotani, we employ a reduced form approach for our empirical specification in a non-separable household model. In this approach, it is assumed that the electricity demand is a function of exogenous variables. In order to determine the elasticities for these independent variables, we estimate the following general model based on available data:

$$
\begin{aligned}
& \log D E=\beta 0+\beta 1 \log I+\beta 2 \log U \\
& +\beta 3 \log H S+\beta 4 \log M E+\beta 5 \log L F
\end{aligned}
$$

where Tobit regression is applied in the equation to handle zero values of the logarithms in the data set

Per capita income (I) and Utility (U) are defined as the ratio of total income and the difference between income and expenses per month to household size respectively. Household characteristics are represented by household size (HS), household labor force (LF) and the number of household members educated (ME).

Table 3. presents the expected signs of the variables used in the regression analysis. Household size is expected to have a negative effect on the per capita electricity use. The ratio of labor force to household size should have a negative effect on the per capita electricity use because it would mean that less people remain in the house. Similarly, the ratio of mid-educated members to household size may negatively affect the per capita energy use. The income and utility per capita is expected to have a positive effect on the per capita consumption of electricity.

Table 3.

EXPECTED SIGNS OF VARIABLES USED IN THE REGRESSION ANALYSIS.

\begin{tabular}{lc}
\hline \multicolumn{1}{c}{ Independent variables } & $\begin{array}{c}\text { Dependent } \\
\text { variable } \\
\text { (per capita) }\end{array}$ \\
${$\cline { 1 - 1 }$} }$ & - \\
$\begin{array}{l}\text { Mid-education / household } \\
\text { size }\end{array}$ & - \\
$\begin{array}{l}\text { Labor force / household size } \\
\text { Per capita income } \\
\text { Per capita utility }\end{array}$ & + \\
\hline
\end{tabular}

\section{REGRESSION RESULTS}

From the 190 surveys, only 149 observations were used in the regression because some zero values were eliminated by the Tobit regression in the independent and dependent variables.

Table 4. reports the regression results for the per capita consumption of electricity as the independent variable and based on the per capita income and utility, education and labor force per household and household size as the dependent variables.

Per capita income generally has a high positive impact on the per capita consumption of commercial energy such as electricity but per capital utility has a negative low effect. Household size has a significant negative impact on the per capita consumption of electricity in this study. Holding the household aggregate electricity use constant, households with larger number of people can afford smaller per capita electricity use. Jiang and O'Neil (2004), discuss that 
household size is a key determinant of energy demand and our findings confirm this premise.

The ratio of mid-educated household members and household labor force to household size have positive impact on the per capita consumption of electricity. This result shows that households with more labor force people tend to consume more electrical energy, probably because many of these jobs are artisanal and in-house; however this study doesn't distinguish between the numbers of people per household working currently inside the house, so further analysis is required.

Table 4.

TOBIT REGRESSION RESULTS FOR PER CAPITA CONSUMPTION OF ELECTRICITY Variables Electricity

\begin{tabular}{|c|c|}
\hline Variables & Electricity \\
\hline Constant & $\begin{array}{c}\text { parameter }^{\mathrm{a}} \\
0,105460 \\
(0,324849)\end{array}$ \\
\hline Income per capita & $\begin{array}{c}0,434916 \\
(3,029988)\end{array}$ \\
\hline Utility per capita & $\begin{array}{c}-0,063835 \\
(-1,133225)\end{array}$ \\
\hline Education/household size & $\begin{array}{c}0,214537 \\
(1,604480)\end{array}$ \\
\hline Labor force/household size & $\begin{array}{c}0,299236 \\
(2,073887)\end{array}$ \\
\hline Household size & $\begin{array}{c}-0,180421 \\
(-1,005206)\end{array}$ \\
\hline $\mathrm{LR}^{\mathrm{b}}$ & $9584,74(0.00)$ \\
\hline
\end{tabular}

a $\mathrm{Z}$-statistic in parentheses.

b Likelihood ratio value, and p-value for insignificance of all independent variables in parentheses.

\section{CONCLUSIONS}

We evaluated household electricity consumption in the marginal area of Guayaquil based on survey data. To our knowledge, this is the first study to examine the key determinants for household's electricity consumption in marginal areas of the country involving (i) socio-economic variables such as income per capita, and utility per capita, (ii) household characteristics like household size, ratios of labor and mid-educated people per household and (iii) Monte Sinai's twelve neighborhoods, notable for their high variation in socio-economic levels, household settings and electricity consumption patterns.

First, we identify the primary role of income and utility levels in the consumption of electricity in marginal areas. A surprising result is that the ratio of labor house to household size affects positively the electricity consumption of the households. A possible explanation is that most people have artisan jobs and develop their economic activities in-house. Additional research is needed to test this conjecture.
Second, we further find that the size of the households affects negatively the electricity consumption and that households with more educated members consume more electricity. This does not necessarily mean that such households have low respect for the environment.

Finally, another important result is that there is a latent fire hazard for the people that live in this marginal area because, the electrical connections are made in most cases in an artisan way and the in-house wiring has not been selected accordingly to the number of appliances and their demand.

Overall, our research proves that people from this marginal area do not have real awareness of their level of consumption and the way it can affect the household utility. Government projects should aim at providing training for the inhabitants of the sector in energy efficiency and security. Also, policies to stimulate basic education in remote marginal areas that are likely to reduce the consumption of electricity should be put in place.

Future investigations could try to stratify the monthly consumption of electricity per household for a longer period in order to characterize in detail the electricity demand in more detail.

\section{REFERENCES}

[1] Chris Howorth, Phil O'Keefe, Ian Convery. «Energy utilisation in periurban areas: issues of demand.» Energy for Sustainable Development Volume 17, Issue 6, 2013: 596-604.

[2] Consejo Nacional de Electricidad. https://www.celec.gob.ec/electroguayas/index.php/30-noticias/61-planmaestro-de-electrificacion-2013-2022.

[3] Instituto Nacional de Estadísitcas y Censos. «Censo de Población y Vivienda.» 2010. http://www.ecuadorencifras.gob.ec/censo-de-poblaciony-vivienda/.

[4] Iwan Sukarno, Hiroshi Matsumoto, Lusi Susanti. «Household lifestyle effect on residential electrical energy consumption in Indonesia: On-site measurement methods.» Urban Climate 20, 2017: 20-32.

[5] Kautsari Anggun Karisma, Ghozali Maski, Iswan Noor. «ANALYSIS OF ELECTRICITY CONSUMPTION BEHAVIOUR: CASE STUDY OF NON BUSINESS AND BUSINESS HOUSEHOLD IN MALANG CITY.» International Journal of Social and Local Economic Governance Vol 2, 2016: 168-176.

[6] Kemmler, Andreas. «Factors influencing household access to electricity in India.» Energy for Sustainable Development Volume 11, Issue 4, 2007 : 13-20.

[7] Le Chen, Nico Heerink, Marrit van den Berg. «Energy consumption in rural China: A household model for three villages in Jiangxi Province.» Ecological Economics 58, 2005: 407-420.

[8] Leiwen Jiang, Brian C. O'Neil. «The energy transition in rural China.» Global Energy Issues, 21, 2004: 2-26.

[9] Melek Yalcintas, Abidin Kaya. «Roles of income, price and household size on residential electricity consumption: Comparison of Hawaii with similar climate zone states.» Energy Reports 3, 2017: 109-118.

[10] Muhammad Ery Wijaya, Tetsuo Tezuka. «A comparative study of households' electricity consumption characteristics in Indonesia: A

16 $^{\text {th }}$ LACCEI International Multi-Conference for Engineering, Education, and Technology: "Innovation in Education and Inclusion", 19-21 July 2018, Lima, Peru. 
techno-socioeconomic analysis.» Energy for Sustainable Development 17, 2013: 596-604.

[11] Muhammad Ery Wijaya, Tetsuo Tezuka. «A comparative study of households' electricity consumption characteristics in Indonesia: A techno-socioeconomic analysis.» Energy for Sustainable Development, 17, 2013: 596-604.

[12] Parisa Esmaeilimoakher, Tania Urmee, Trevor Pryor, Garry Baverstock. «Identifying the Determinants of Residential Electricity Consumption for Social Housing in Perth, Western Australia.» Energy and Buildings, 7052, 2016.

[13] Pulak Mishra, BhagirathBehera. «Socio-economic and environmental implications of solar electrification: Experience of rural Odisha .» Renewable and Sustainable Energy Reviews 56, 2015: 953-964.

[14] Qing Xie, Hongbing Ouyang, Xiang Gao. «Estimation of electricity demand in the residential buildings of China based on household survey data.» International journal of hydrogen energy , 2016: 1-8.

[15] Shuwen Niu, Yanqin Jia, Liqiong Ye, Runqi Dai, Na Li. «Survey data on household electricity consumption and living status in Northwestern China.» Data in Brief 7, 2016: 1106-1111.

[16] Taoyuan Wei, Qin Zhu, Solveig Glomsrød. «Energy spending and household characteristics of floating popilation: Evidence from Shanghai.» Energy for Sustainable Development 23, 2014: 141-149.

[17] Valeria Di Cosmo, Denis O'Hora. «Nudging electricity consumption using TOU pricing and feedback: evidence from Irish households.» Journal of Economic Psychology 61, 2017: 1-14.

[18] Zhang Jingchao, Koji Kotani. «The determinants of household energy demand in rural Beijing: Can environmentally friendly technologies be effective?» Energy Economics 34, 2011: 381-388.

[19] Zhifeng Guo, Kaile Zhou, Chi Zhang, Xinhui Lu, Wen Chen, Shanlin Yang. «Residential electricity consumption behavior: Influencing factors, related theories and intervention strategies.» Renewable and Sustainable Energy Reviews, 81, 2017: 399-412.

16 $^{\text {th }}$ LACCEI International Multi-Conference for Engineering, Education, and Technology: "Innovation in Education and Inclusion", 19-21 July 2018, Lima, Peru. 